\title{
Das Spannungsverhältnis zwischen Schiedsrichter und Parteivertreter in der internationalen Schiedsgerichtsbarkeit
}

Insbesondere unter den IBA Guidelines on Party Representation in International Arbitration

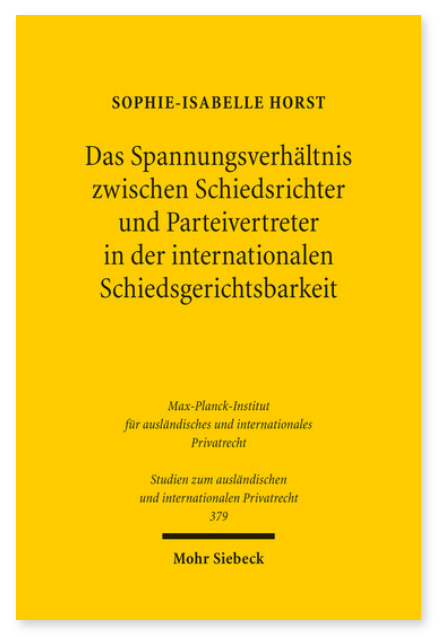

2017. XXII, 299 Seiten. StudIPR 379

ISBN 978-3-16-155314-1

DOI 10.1628/978-3-16-155314-1

eBook PDF 79,00€

ISBN 978-3-16-155185-7

fadengeheftete Broschur 79,00€
Die Unabhängigkeit und Unparteilichkeit der Schiedsrichter spielen eine entscheidende Rolle in der internationalen Schiedsgerichtsbarkeit. Gleiches gilt für das Recht der Schiedsparteien auf freie Auswahl ihrer Parteivertreter. Beide Rechtspositionen kollidieren, wenn zwischen Schiedsrichter und Parteivertreter eine Verbindung besteht, die die Unvoreingenommenheit des Schiedsrichters gefährdet. Sophie-Isabelle Horst untersucht das Spannungsverhältnis zwischen Schiedsrichter und Parteivertreter insbesondere im Hinblick auf die Schiedsrichterablehnung und die Rolle der Schiedsparteien bei der Vermeidung von Interessenkonflikten. Ein weiterer Schwerpunkt der Arbeit liegt auf der Vermeidung von Interessenkonflikten und dem Ausschluss des Parteivertreters nach den im Jahr 2013 veröffentlichten IBA Guidelines on Party Representation in International Arbitration.

Sophie-Isabelle Horst Geboren 1987; Studium der Rechtswissenschaft an der Universität Hamburg; seit 2014 Promotionsstudium an der Universität Hamburg; derzeit Rechtsreferendarin am Hanseatischen Oberlandesgericht Hamburg.
Jetzt bestellen:
https://mohrsiebeck.com/buch/das-spannungsverhaeltnis-zwischen-schiedsrichter-und-parteivertreter-in-der-
internationalen-schiedsgerichtsbarkeit-9783161553141?no_cache=1
order@mohrsiebeck.com
Telefon: +49 (0)7071-923-17
Telefax: +49 (0)7071-51104 